\title{
Birth prevalence
}

INSERM

\section{Source}

INSERM. (1999). Orphanet: an online rare disease and orphan drug data base. birth prevalence. ORPHA:409968

Number of cases observed at birth relative to the number of children born alive at a given moment. 